\title{
Febre tifóide: recaída por resistência antimicrobiana. Relato de caso
}

\author{
Typhoid fever: relapse due to antimicrobial resistance. Case report \\ Wilson Duarte Alecrim, 2,3, Adalgisa Câmara de Sá Peixoto Loureiro², \\ Ricardo Silva Moraes ${ }^{1}$, Rossicleia Lins Monte ${ }^{2,3}$ e \\ Marcus Vinícius Guimarães de Lacerda²
}

\begin{abstract}
Resumo Relatamos pela primeira vez na Amazônia Brasileira um paciente com febre tifóide, com resistência clínica e laboratorial ao cloranfenicol, droga de escolha para esta doença em nossa região. A recaída foi observada no $7^{\circ}$ dia após o término do tratamento e a paciente foi tratada com ciprofloxacina.
\end{abstract}

Palavras-chaves: Febre tifóide. Cloranfenicol. Recaída. Resistência.

Abstract We report for the first time in the Brazilian Amazon a typhoid fever patient with clinical and laboratorial resistance to chloramphenicol, drug of election for this disease in our region. The relapse was observed at the $7^{\text {th }}$ day after the end of treatment and the patient was treated with ciprofloxacin.

Key-words: Typhoid fever. Chloramphenicol. Relapse. Resistance.

A febre tifóide continua sendo problema de saúde pública em países com precárias condições sanitárias, representando ainda um grande desafio o seu diagnóstico microbiológico, tratamento radical e, conseqüentemente, o controle da endemia. As áreas com maior número de casos não dispõem ainda de laboratório especializado em bacteriologia, motivo pelo qual pouco se conhece a respeito do perfil de resistência da Salmonella aos principais antimicrobianos, nestas localidades.
Muitas vezes, a recaída da doença é atribuída ao tratamento feito de forma inadequada, seja em razão dos efeitos colaterais desencadeados pelo cloranfenicol ou pelo tempo prolongado de tratamento, contribuindo para uma diminuta adesão terapêutica. Acredita-se que algumas destas recaídas se devam também à subnotificada resistência da bactéria ao cloranfenicol e a outros antimicrobianos de primeira linha para o tratamento da febre tifóide.

\section{RELATO DO CASO}

Paciente do sexo feminino, de 11 anos de idade, procedente de Coari, AM, no médio Rio Solimões, procurou a Fundação de Medicina Tropical do Amazonas (FMT/IMT-AM) com história de onze dias de febre alta contínua. O exame físico era normal. Hemograma e análise bioquímica do sangue estão demonstrados na Tabela 1. A pesquisa de Plasmodium $s p$, ao exame da gota espessa e QBC, foi negativa. O teste de aglutinação (reação de Widal) foi reativo apenas para o antígeno O de Salmonella typhi (diluição 1/20).

Com base em critérios clínico-epidemiológicos, foi feito o diagnóstico de febre tifóide. Tendo em vista o bom nível de esclarecimento da família, optou-se pelo tratamento ambulatorial com cloranfenicol, na dose de
$50 \mathrm{mg} / \mathrm{kg} / \mathrm{dia}$. Como a criança não apresentava melhora, no sexto dia de tratamento voltou a procurar a FMT/ IMT-AM, sendo então internada na Enfermaria de Pediatria da Unidade de Internação Nelson Antunes daquela instituição, para observação e administração supervisionada da medicação. Mantinha picos febris de até $39^{\circ} \mathrm{C}$. O restante do exame físico era normal. Apresentava análise de urina e exame parasitológico de fezes normais, coprocultura, urinocultura, duas hemoculturas sem evidências de crescimento bacteriano e ultrassonografia abdominal mostrando discreta hepatomegalia. $\mathrm{O}$ teste de aglutinação foi repetido (doze dias após o primeiro), e foi reativo para o antígeno $\mathrm{H}$ de S. typhi (diluição 1/160). Optou-se pela continuação do

\footnotetext{
1. Fundação Universidade do Amazonas, Manaus, AM. 2. Fundação de Medicina Tropical do Amazonas, Manaus, AM. 3. Universidade do Estado do Amazonas, Manaus, AM.

Endereço para correspondência: Prof. Wilson Duarte Alecrim. Av. Pedro Teixeira, 25, Planalto, 69040-000 Manaus, AM, Brasil

Telefone: 5592 238-1146; fax: 5592 238-7220

e-mail:walecrim@uol.com.br

Recebido para publicação em 27/8/2001.
} 
tratamento com cloranfenicol e a criança tornou-se apirética no $11^{\circ}$ dia após início do tratamento. Recebeu alta hospitalar e continuou o cloranfenicol por mais cinco dias, concluindo tempo total de tratamento de 16 dias. Uma semana após o término do tratamento, voltou a apresentar febre, sem nenhum outro sintoma. Foi realizada nova hemocultura, com isolamento de bastonetes Gram-negativos com características morfotintoriais e bioquímicas de germe pertencente ao gênero Salmonella, sendo identificado como S. typhi (utilizando-se os meios TSI, Rugai-Pessoa e Silva-Rugai modificados). Na Tabela 2, está assinalado o perfil de resistência antimicrobiana da bactéria isolada, utilizando-se técnica semi-quantitativa preconizada por Kirby \& Bauer (NCCLS,2000), com polidiscos 21 Victor Lorianâ (Produtos Químicos Lorian â LTDA). Em função das evidências clínicas e laboratoriais de resistência da bactéria isolada ao cloranfenicol, fez uso de ciprofloxacina (250mg, oral, a cada $12 \mathrm{~h}$ ) por sete dias, com apirexia no terceiro dia de tratamento. Duas coproculturas subseqüentes, realizadas com intervalos de 15 dias, não evidenciaram crescimento bacteriano.

\begin{tabular}{|c|c|c|}
\hline & $1^{\circ}$ dia de tratamento & $8^{\circ}$ dia de tratamento \\
\hline Leucócitos $\left(10^{3} / \mu \mathrm{l}\right)$ & 6,0 & 3,8 \\
\hline Neutrófilos (\%) & 64 & 28 \\
\hline Linfócitos (\%) & 30 & 69 \\
\hline Monócitos (\%) & 6 & 3 \\
\hline Eosinófilos (\%) & 0 & 0 \\
\hline Bastões (\%) & 0 & 0 \\
\hline Hemácias $\left(10^{6} / \mu \mathrm{l}\right)$ & 4,27 & 3,45 \\
\hline Hemoglobina (g/dl) & 11,3 & 9,3 \\
\hline Hematócrito (\%) & 34,6 & 28,2 \\
\hline Plaquetas $\left(10^{3} / \mu \mathrm{l}\right)$ & 300 & 233 \\
\hline Bilirrubina total (mg/dl) & 0,34 & 0,36 \\
\hline Bilirrubina direta $(\mathrm{mg} / \mathrm{dl})$ & 0,10 & 0,09 \\
\hline AST (U/I) & 89 & 71 \\
\hline ALT (U/I) & 91 & 61 \\
\hline $\mathrm{FAL}(\mathrm{U} / \mathrm{I})$ & - & 214 \\
\hline$\gamma \mathrm{GT}(\mathrm{U} / \mathrm{I})$ & - & 87 \\
\hline
\end{tabular}

Tabela 2 - Antibiograma de S. typhi isolada na hemocultura colhida após o tratamento com cloranfenicol.

\begin{tabular}{lc}
\hline Antibiótico testado & Resultado \\
\hline Amicacina & ++ \\
Ampicilina & ++ \\
Carbenicilina & - \\
Cefalotina & ++ \\
Cefoxitina & ++ \\
Ceftazidima & ++ \\
Ceftriaxona & ++ \\
Ciprofloxacina & ++ \\
Clindamicina & - \\
Cloranfenicol & - \\
Eritromicina & - \\
Gentamicina & - \\
Imipenem & ++ \\
Nitrofurantoína & ++ \\
Norfloxacina & - \\
Oxacilina & ++ \\
Penicilina & - \\
Rifampicina & - \\
Tetraciclina & ++ \\
Tobramicina & - \\
Trimetoprim+sulfametoxazol & - \\
\hline & ++
\end{tabular}

++ sensível + pouco sensível - resistente 


\section{DISCUSSÃO}

No caso relatado, a despeito da discussão quanto à terapêutica, notamos que o quadro clínico se resume à síndrome febril, estando ausentes os clássicos sinais e sintomas da febre tifóide, como diarréia, hepatoesplenomegalia ou pancitopenia ao hemograma. É, no entanto, a partir da síndrome febril indiferenciada, que fazemos, muitas vezes, este diagnóstico, em nossa região, especialmente nas primeiras duas semanas da doença.

A Amazônia Brasileira é responsável por mais da metade dos casos de febre tifóide notificados em nosso país ${ }^{6}$, possivelmente por apresentar condições sanitárias deficientes. Apesar da preconização do uso de quinolonas (mesmo em crianças ${ }^{11}$, apesar de sua questionável toxicidade sobre tecidos cartilaginosos humanos) ou cefalosporinas de terceira geração como primeira escolha no tratamento da febre tifóide, em alguns países ${ }^{1}$, temos optado ainda pelo uso do cloranfenicol, em função de seu baixo custo e resposta terapêutica satisfatória, a despeito de seus efeitos adversos. Embora Cunha e cols ${ }^{5}$ tenham demonstrado, em 1981, 100\% de sensibilidade da S. typhi ao cloranfenicol, em diferentes estados brasileiros, outros trabalhos evidenciam a resistência da bactéria a este antibiótico desde a década de 60 , em outros países e também no Brasil 23814 .

Trata-se do primeiro caso de resistência in vitro e in vivo de S. typhi ao cloranfenicol relatado na Amazônia Brasileira. A resistência à droga deve ser considerada em todos os casos de recaída (retorno dos sintomas até 15 dias após o término do tratamento), excluindose outras causas comuns de recaída ${ }^{9}$, como a má qualidade da droga administrada, administração incorreta, tempo inadequado de tratamento ou condição subjacente que não permita a esterilização bacteriana (e.g., litíase biliar). Eventualmente, as bactérias resistentes são responsáveis por epidemias de febre tifóide, como a do México, em 1972 , com observação de $75 \%$ de resistência da S. typhi ao cloranfenicol ${ }^{15}$.

A resistência da Salmonella a antibióticos de uso rotineiro é um problema de saúde pública, contribuindo para a perpetuação desta endemia em nosso meio, além das cepas resistentes apresentarem mais recaídas, mais complicações clínicas $^{10}$, retardo da apirexia e, conseqüentemente, maior tempo de internação hospitalar, sobrevindo daí o aumento dos custos. A MDRST (multidrug-resistant $S$. typhi) já é um problema em países como Índia ${ }^{4}$, Quênia ${ }^{7}$ e Paquistão ${ }^{12}{ }^{13}$, provavelmente em função do uso indiscriminado e inadequado de antibióticos, tanto em homens quanto em animais, já que a pressão seletiva destas drogas sobre bactérias de interesse veterinário também influencia o perfil de sensibilidade de bactérias patogênicas ao homem, por troca de plasmídeos $\mathrm{R}$, principais responsáveis pelo mecanismo de resistência.

Em casos semelhantes ao relatado, quando houver recaída clínica, deve-se sempre levar em consideração a possibilidade de resistência da S. typhi ao cloranfenicol.

\section{REFERÊNCIAS BIBLIOGRÁFICAS}

1. Ackers ML, Puhr ND, Tauxe RV, Mintz ED. Laboratory-based surveillance of Salmonella serotype typhi infections in the United States: antimicrobial resistance on the rise. Journal of the American Medical Association 283: 2668-2673, 2000.

2. Angulo GB, Velarde MAPL, Romo MR, Escobedo $\mathrm{CH}$, Quintana JM. Fiebre tifoidea: diagnóstico de laboratorio, fagotipos y resistencia al cloranfenicol (1972-1982). Análisis de dos mil casos comprobados bacteriológicamente. Revista Médica del Instituto Mexicano del Seguro Social 22: 7-13, 1984.

3. Asensi MD, Hofer E. Serovars and multiple drug resistant Salmonella $s p$ isolated from children in Rio de Janeiro - Brazil. Revista de Microbiologia de São Paulo 25: 149-153, 1994.

4. Chandel DS, Chaudhry R, Dhawan B, Pandey A, Dey AB. Drugresistant Salmonella enterica serotype paratyphi A in India. Emerging Infectious Diseases 6: 420-421, 2000.

5. Cunha MAS, Suassuna IR, Suassuna I. Sensibilidade de Salmonella typhi a antimicrobianos em emprego clínico. Revista da Associação Médica Brasileira 27: 267-268, 1981.

6. Fundação Nacional de Saúde, Centro Nacional de Epidemiologia; Relatório de doenças emergentes e re-emergentes no Brasil, Ministério da Saúde, Brasília, DF. 1999/2000.

7. Kariuki S, Gilks C, Revathi G, Hart A. Genotypic analysis of multidrug-resistant Salmonella enterica serovar typhi, Kenya. Emerging Infectious Diseases 6: 649-651, 2000.
8. Medellín AM, López MEC, Garduño RL. Aislamientos resistentes a antibióticos. Infectologia 12: 519-525,1986.

9. Okeke IN, Lamikanra A, Edelman R. Socioeconomic and Behavioral Factors Leading to Acquired Bacterial Resistance to Antibiotics in Developing Countries. Emerging Infectious Diseases 5: 18-27, 1999.

10. Palomino WC, Aguad RL, Rodriguez LM, Cofre GG, Villanueva $J$. Evolución clínica de algunos casos de fiebre tifoidea y paratifus A y $B$ en relación a la sensibilidad del agente etiológico al cloramfenicol. Revista Médica de Chile 114: 919-92, 1986.

11. Rathish KC, Chandrashekar MR, Nagesha CN. An outbreak of multidrug resistant typhoid fever in Bangalore. Indian Journal of Pediatrics 62: 445-448, 1995.

12. Saqib A, Ahmed A. Culture and sensitivity of Salmonella species: analysis of a two-year data. Journal of the Pakistan Medical Association 50: 282-284, 2000.

13. Shanahan PM, Karamat KA, Thomson CJ, Amyes SG. Characterization of multi-drug resistant Salmonella typhi isolated from Pakistan. Epidemiology and Infection 124: 9-16, 2000.

14. Solórzano-Santos F, Leaños MB, Guiscafré GH. Resistência antimicrobiana actual de Salmonella typhi, Salmonella enteritidis y Shigella $s p$ Boletín Médico del Hospital Infantil de México 44: 448-455, 1987.

15. Solórzano-Santos F, Miranda-Novales MG. Resistencia de bacterias respiratorias y entéricas a antibióticos. Salud Pública de México 40: 510-516, 1998. 